\title{
FRACTURE TOUGHNESS OF THIN PLATES BY THE DOUBLE-TORSION TEST
} METHOD

Jonathan A. Salem

NASA Glenn Research Center

Cleveland, $\mathrm{OH}, 44135$

Miladin Radovic, Edgar Lara-Curzio and George Nelson

Oak Ridge National Laboratory

Oak Ridge, TN 37831

\section{ABSTRACT}

Double torsion testing can produce fracture toughness values without crack length measurement that are comparable to those measured via standardized techniques such as the chevron-notch, surface-crack-in-flexure and precracked beam if the appropriate geometry is employed, and the material does not exhibit increasing crack growth resistance. Results to date indicate that $8<W / d<80$ and $L / W>2$ are required if crack length is not considered in stress intensity calculations. At $L / W=2$, the normalized crack length should be $0.35<a / L<0.65$; whereas for $L / W=3,0.2<a / L<0.75$ is acceptable. In addition, the load-points need to roll to reduce friction. For an alumina exhibiting increasing crack growth resistance, values corresponding to the plateau of the R-curve were measured. For very thin plates $(W / d>80)$ nonlinear effects were encountered.

\section{INTRODUCTION}

Many emerging commercial structures such as fuel cell elements and diesel particulate filters consist of thin brittle plates. The fracture toughness of such thin plates is of interest for materials assessment and life prediction. In 2001, American Society for Testing and Materials (ASTM) committee C28 on Advanced Ceramics developed standard test method C1421, Standard Test Method for Determination of the Fracture Toughness of Advanced Ceramics at Ambient Temperatures. ${ }^{1} \mathrm{C} 1421$ covers the determination of $K \mathrm{~B}_{I p b \mathrm{~B}}$ (pre-cracked beam), $K \mathrm{~B}_{I s c \mathrm{~B}}$ (surface crack in flexure) and $K \mathrm{~B}_{I v b \mathrm{~B}}$ (chevron-notched beam). Unfortunately, none of these test configurations is amenable to evaluate materials in the form of thin plates.

In this investigation, the double-torsion test method ${ }^{2,3}$ was used to determine the fracture toughness of materials that were previously measured using ASTM C 1421. Test specimens of various thicknesses were cut and machined from billets and tested in comparable environments in order to compare DT (double-torsion) results to standardized beam results. In addition to the effect of thickness, the influences of crack curvature and crack length on fracture toughness were investigated. As the test section (plate) becomes thin the overall stress state changes from plane strain to plane stress and nonlinear effects can occur. Little study of this effect has been performed for ceramic materials, though tests on relatively thick sections ranging from $5 \mathrm{~mm}$ to $15 \mathrm{~mm}$ indicated no influence on the measured fracture toughness ${ }^{4}$.

Three objectives were sought in this work: (1) to determine the effect of section thickness on the measured fracture toughness using the DT test specimen; (2) to compare the DT test to accurate, well documented standardized test techniques such as the SEPB (single-edgedprecracked-beam), CN (chevron-notch) and SCF (surface crack in flexure); and (3) lay the 
foundation for an ASTM standard on the DT test specimen. Because so much controversy exists regarding the DT specimen ${ }^{5}$, a direct experimental approach was taken by using model materials: $\alpha$ silicon carbide, alumina, and soda-lime silicate glass. Alpha silicon carbide is stiff, has consistent fracture toughness with little R-curve behavior, and is very insensitive to stress corrosion. Alumina is more difficult for such a study because it can exhibit a rising R-curve, stress corrosion, and textural effects. ${ }^{6}$ Soda-lime glass, though sensitive to stress corrosion, has a flat R-curve. In addition, its transparency allows easy observation of the crack length. To insure consistent results, test specimens were cut from bulk sections and tested in comparable environments.

\section{EXPERIMENTAL PROCEDURES}

Materials, Machining, and Precracking

The fracture toughness of the reference $\alpha \mathrm{SiC}$ (Hexoloy SA) and isopressed $96 \%$ alumina (ALSIMAG 614) were previously measured ${ }^{4}$ and are summarized in Table I. DT test specimens measuring $W=23.5 \mathrm{~mm}$ by $L=51 \mathrm{~mm}$ were machined from billets of the same lots. The specimen thicknesses ranged from $d=0.25$ to $3 \mathrm{~mm}$ and were chevron-notched to $25 \%$ of the length to allow rapid precracking to the mid-section. For the glass test specimens, precracking was initiated from six Vicker's indentations made at one end of the test specimen with 3 to $5 \mathrm{~kg}$ load. Precracking was performed by rapidly loading to $\sim 3 / 4$ of the expected load and then slowly loading at a stroke rate of 0.002 to $0.005 \mathrm{~mm} / \mathrm{min}$ until a crack formed and grew to the desired length. Once precracked, the specimens were unloaded for crack length measurement and then failed at a stroke rate of $2 \mathrm{~mm} /$ minute. Specimen width to depth of $6<W / d<15$, length to width of $L / W>2$, and crack length of $W<a<L-W$ have been recommended ${ }^{3,5}$. The ratios employed herein are $W / d=8$ to $16, L / W=2.1$, and $a / L \approx 0.4$ for the glass specimens, and $W / d=8$ to $90, L / W=2.1$, and $0.4<a / L<0.5$ for the ceramics. Although side grooves of $\sim 1 / 2$ the depth have been suggested, none were employed herein. Fracture toughness was calculated from $^{2}$

where

$$
\begin{gathered}
K_{I d t}=P_{\max } W_{m}\left(\frac{3}{W d^{4}(1-i) \varnothing}\right)^{1 / 2} \\
K_{I d t}=P_{\max } W_{m}\left(\frac{3(1+i)}{W d^{4} \varnothing}\right)^{1 / 2} \\
\varnothing=1-1.2604 \frac{d}{W}+2.40 \frac{d}{W} \exp \left(-\partial \frac{W}{d}\right) .
\end{gathered}
$$

and $P$ is the applied force, $d$ the plate thickness, $W$ the plate width, $W_{m}$ the moment arm, and is Poison's ratio ${ }^{2}$. The term $\psi$ is a thickness correction factor to account for interaction of the torsion arms. It approaches unity at $W / d \approx 50$. The specimen thickness, $d$, is raised to the fourth power and thus must be measured carefully for thin plates. 
Table I. Fracture toughness and standard deviation measured by the methods specified in ASTM C 1421. Results in any row are for the same billet and have identical test orientation except as noted. The number of tests is given in parenthesis.

\begin{tabular}{|l|c|c|c|}
\hline \multicolumn{1}{|c|}{ Material } & $\begin{array}{c}K \mathrm{~B}_{I v b \mathrm{~B}}(A) \\
\mathrm{MPa} \sqrt{\mathrm{m}}\end{array}$ & $\begin{array}{c}K \mathrm{~B}_{I p b \mathrm{~B}} \\
\mathrm{MPa} \sqrt{\mathrm{m}}\end{array}$ & $\begin{array}{c}K \mathrm{~B}_{I s c \mathrm{~B}} \\
\mathrm{MP} \sqrt{\mathrm{m}}\end{array}$ \\
\hline$\alpha$-SiC (JAS) & $2.61 \pm 0.05(6)$ & $2.58 \pm 0.08(4) \mathrm{P}^{*}$ & $2.76 \pm 0.08(4)$ \\
\hline ALSIMAG 614 & $3.19 \pm 0.06(7)$ & $\begin{array}{l}3.09 \pm \quad 0.17 \\
(13) \mathrm{P}^{* \mathrm{PPP}}\end{array}$ & $3.18 \pm 0.10(5)$ \\
\hline
\end{tabular}

* Different billet from the same material batch as the VB geometry $A$ specimens.

\section{Effect of Friction}

The effect of friction was investigated by testing glass plates in a $\mathrm{SiC}$ fixture with fixed loading balls and various lubricants, and by using a steel fixture that allowed the $4 \mathrm{~mm}$ diameter $\mathrm{SiC}$ loading balls to rotate, Figure 1. The ball O.D. and specimen edge were aligned to ensure a consistent definition of crack length relative to load point. Balls were used instead of pins because the plate bends in two planes, thereby shifting the point of loading for rods. The results are summarized in Figure 2 and indicate that lubricants such as vacuum grease, graphite foil, and PTFE tape, though lowering the results toward the expected value $(\sim 0.76 \mathrm{MPa} \sqrt{\mathrm{m}})$ are not completely sufficient. Use of load balls that are free to roll in one dimension reduced the measure fracture toughness by $\sim 5 \%$. The effect was measured by using both 1.5 and $3.0 \mathrm{~mm}$ thick plates. The use of an excessively thick plate $(W / d=8)$ increases the result $\sim 4 \%$.
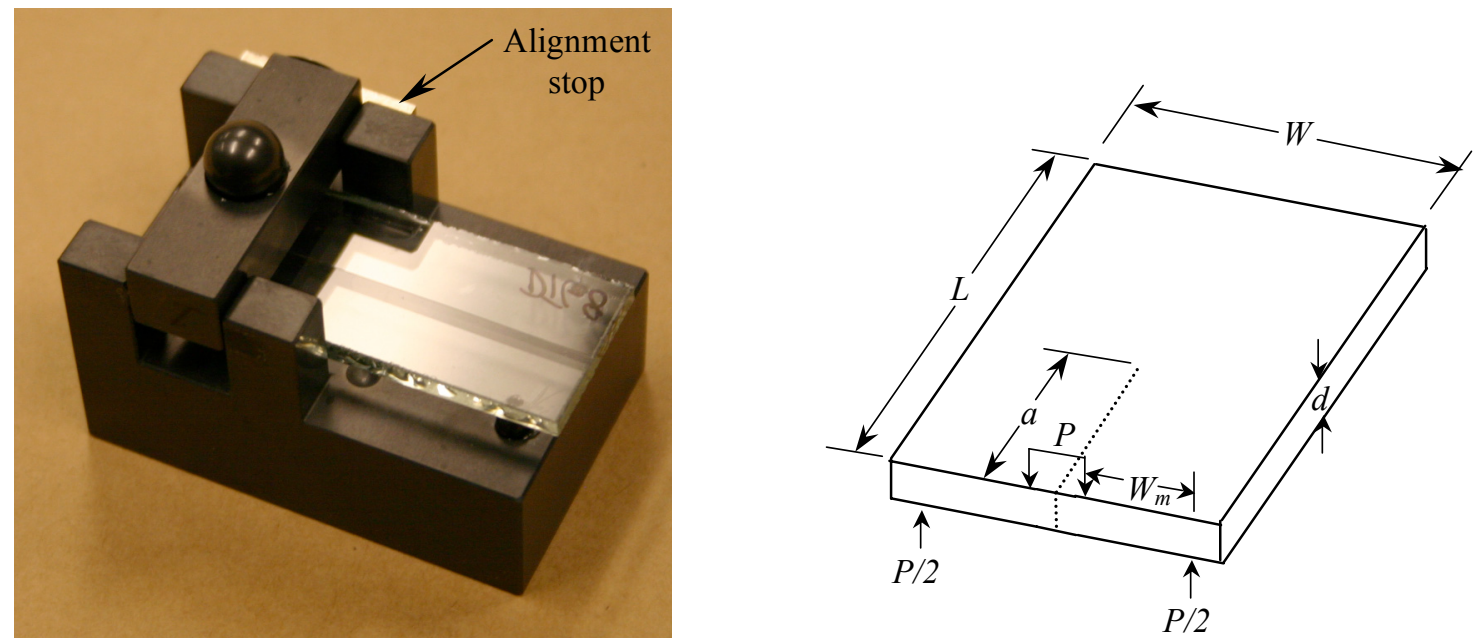

Figure 1-DT test specimen and fixture use this study. 


\section{Effect of Crack Length}

The DT specimen exhibits relatively consistent stress intensity factor as a function of crack length. In order to determine the range in which consistent results are obtained under typical laboratory conditions and procedures for a relatively short plate, glass specimens were tested at $2 \mathrm{~mm} / \mathrm{min}$ and $\sim 45 \% \mathrm{RH}$ (relative humidity). The results shown in Figure 3 indicate that $\sim$ of a test specimen with $L / W=2$ will yield consistent results for a material that is sensitive to stress corrosion. Outside of this range, the results increase rapidly for short cracks and decrease rapidly for long cracks. This indicates a slightly less useful range than the $W<a<$ $L-W$ recommendation $^{3}$ which was based on $L / W=3$. Load-displacement diagrams for shorter cracks exhibited a peak followed by a plateau.

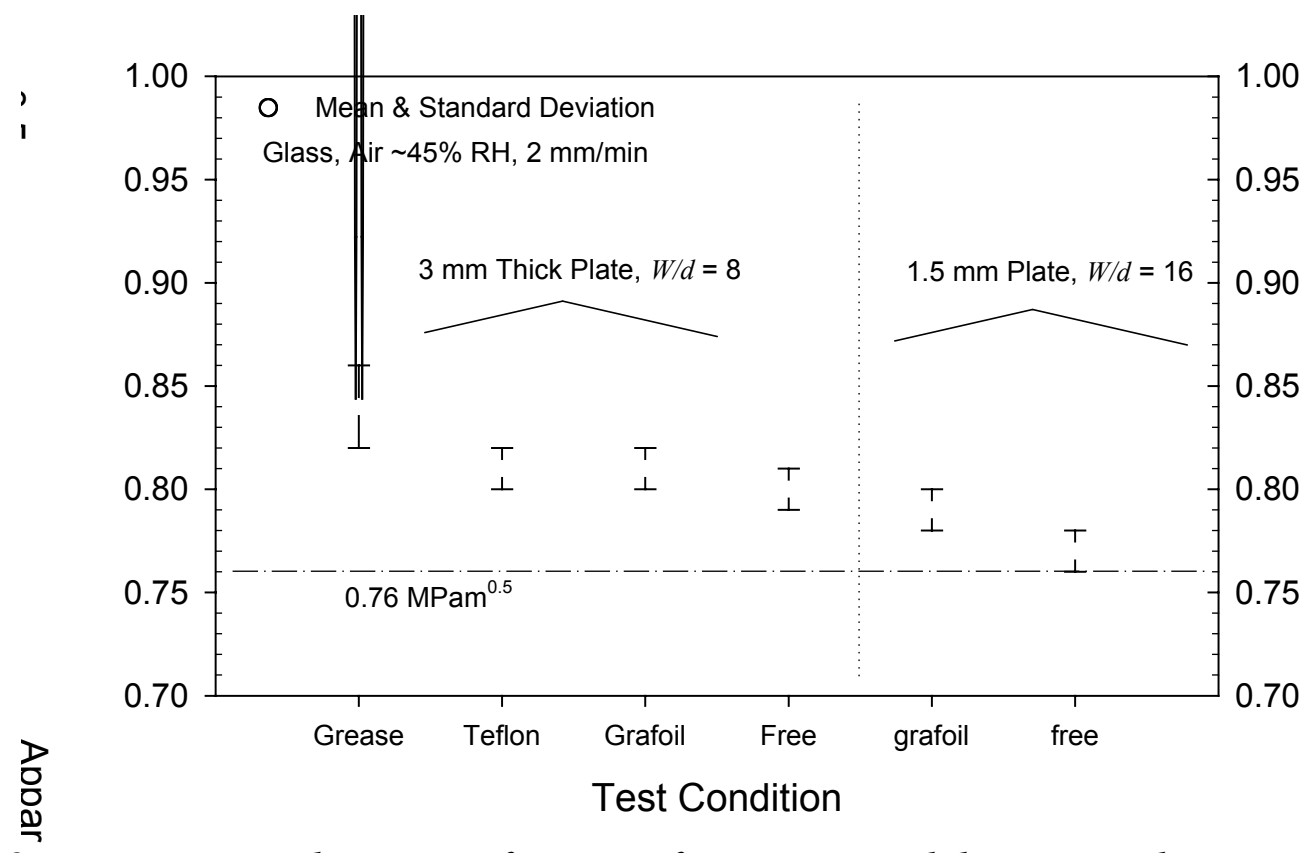

Figure 2 - Fracture toughness as a function of contact point lubricant in glass specimens tested at $2 \mathrm{~mm} / \mathrm{min}$ in $45 \%$ RH air. For the plate, $L=51 \mathrm{~mm}, w=23.5 \mathrm{~mm}, W \mathrm{~B}_{L \mathrm{~B}}=5 \mathrm{~mm}, W \mathrm{~B}_{S_{\mathrm{B}}}=20$ $\mathrm{mm}, d=1.5 \mathrm{~mm}$. 


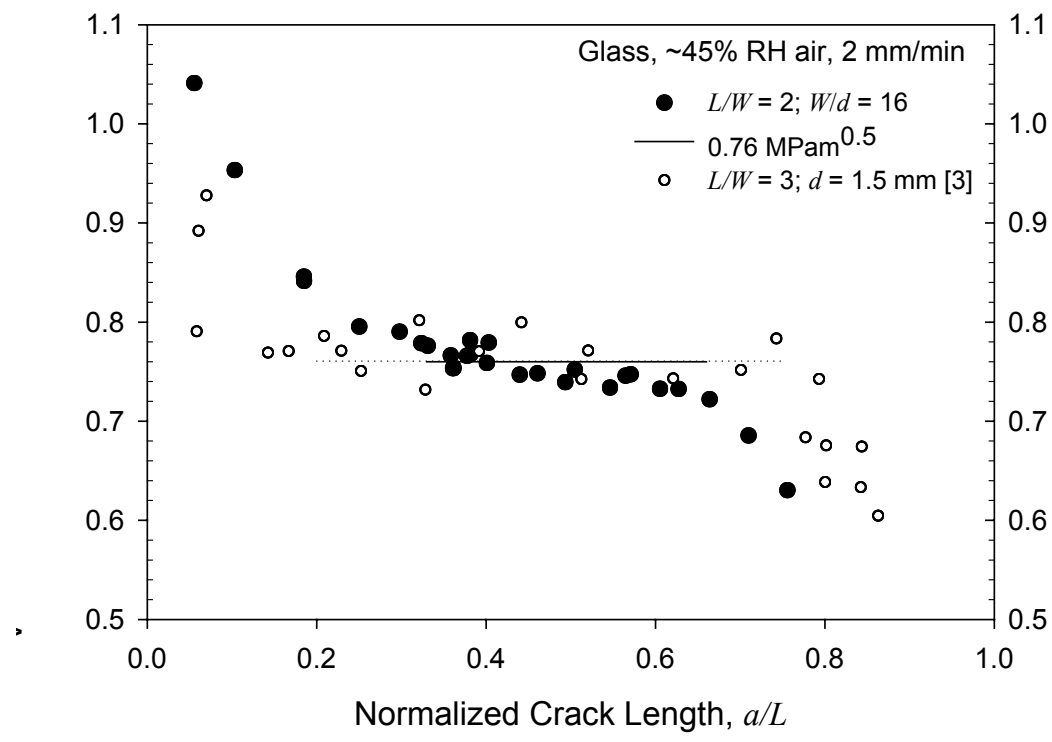

Figure 3 - Fracture toughness as a function of normalized crack length in glass specimens tested at $2 \mathrm{~mm} / \mathrm{min}$ in $45 \% R H$ air. For the plate, $L=51 \mathrm{~mm}, W=23 \mathrm{~mm}, W \mathrm{~B}_{L \mathrm{~B}}=5 \mathrm{~mm}, W \mathrm{~B}_{S_{\mathrm{B}}}=20$ $\mathrm{mm}, d=1.5 \mathrm{~mm}$. The fixture was steel with $\alpha \mathrm{SiC}$ load balls that were free to roll. Open symbols are data of Pletka et al ${ }^{3}$.

\section{Effect of Crack Position and Resultant Curvature}

Poor crack plane alignment relative to the spans and specimen $W$ causes the crack to curve to one side rather than extending along the specimen centerline. To investigate the effect on measured fracture toughness, tests were run with the crack purposely offset relative to the centerline of $W$ and with the upper span misaligned relative to the lower span. The effect of crack offset, which changes the torsional stiffness of each arm, is shown in Figure 4 and indicates that the notch or precrack should be placed on center within $1 \%$ of $W(0.25 \mathrm{~mm}$ in this case), and thereby break out of the specimen end rather than the side. The effect of offsetting the upper span relative to the lower span with the crack placed on the specimen centerline had little effect for offsets less than $\sim 1 / 2 \mathrm{~mm}$. This seems unusual, because the moment applied to each arm should be changing. The lack of a measured effect may in part be due to the stop used to position the loading span (see figure 1). The stop prevents rotation of the upper span and thereby forces it to apply a more uniform displacement to each arm. With a well made fixture and some care in alignment via the unaided eye, specimens can be cracked down the centerline repeatedly. 


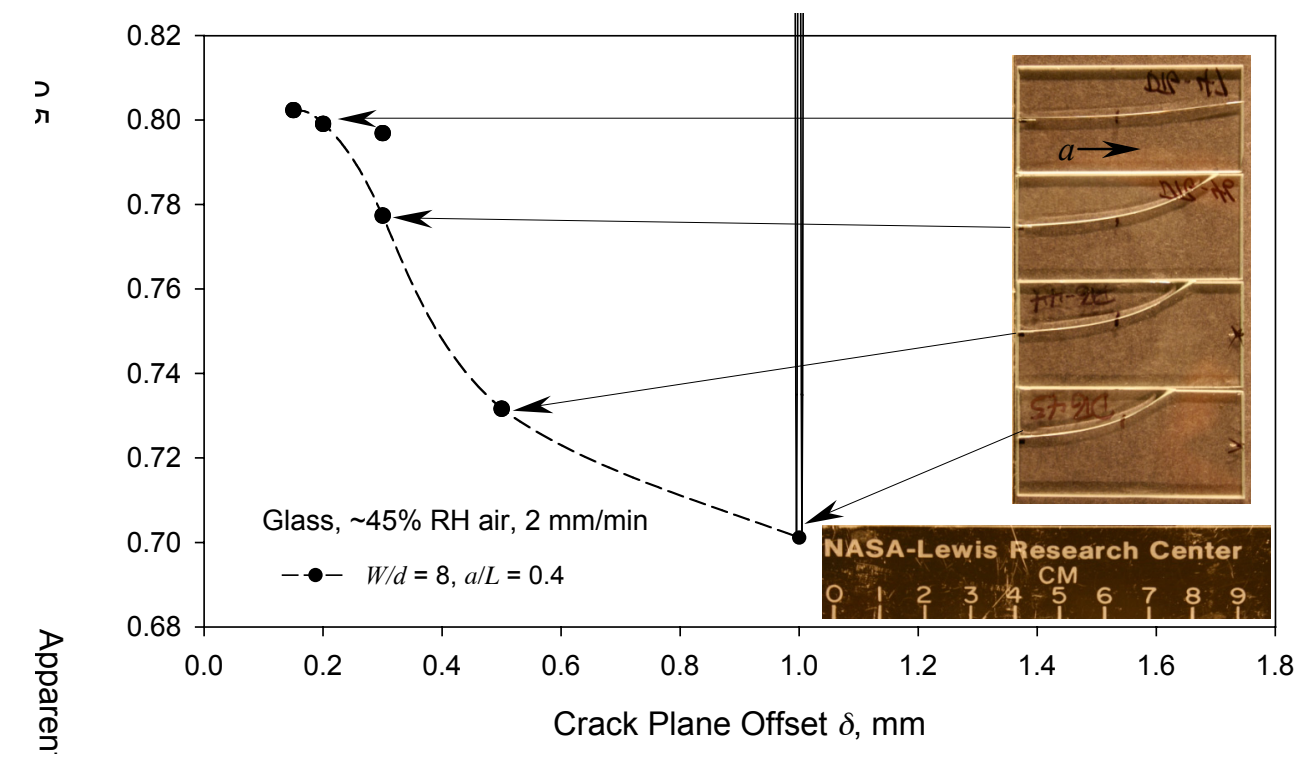

Figure 4 -Fracture toughness as a function of crack plane offset in glass specimens tested at 2 $\mathrm{mm} / \mathrm{min}$ in $45 \%$ RH air. The spans and specimen were centered, and the crack plane offset within the specimen. Crack trajectories associated with different offsets are shown in the inset.

\section{Effect of Loading Rate}

The effect of loading rate on the measured fracture toughness of glass was investigated by testing at rate of $0.2 \mathrm{~mm} /$ minute instead of the usual $2 \mathrm{~mm} / \mathrm{min}$. Four tests at $0.2 \mathrm{~mm} / \mathrm{min}$ resulted in $0.75 \pm 0.01 \mathrm{MPa} \sqrt{\mathrm{m}}$ while seven tests at $2 \mathrm{~mm} /$ minute resulted in $0.77 \pm 0.01$ $\mathrm{MPa} \sqrt{\mathrm{m}}$, implying some flexibility in stroke rate for materials that are sensitive to stress corrosion.

\section{Effect of Specimen Thickness}

Thickness may influence test results in many ways: (1) Plane stress vs plane strain; (2) nonlinear bending of the test specimen; and (3) textural affects as the specimen thickness approaches the grain size. The effect of specimen thickness was investigated for a wider range of thicknesses by using $\mathrm{SiC}$ and alumina test specimens. Plasticity requirement such as those used in metals (e.g. ASTM E399) are not relevant, as yield is not usually measurable and little plasticity occurs. The degree of elastic constraint is relevant, but the difference in terms of elastic calculation is small (plus $\sim 1 \%$ for $\quad=0.16$ and plus $\sim 5 \%$ for $\quad=0.3$ by assuming plane strain for a very thin specimen actually in plane stress). All calculations herein assumed plane strain.

Figure 5(a) compares fracture toughness of $\mathrm{SiC}$ measured with standard methods and the DT for $a / W=0.4$ to 0.5 and $L / W=2$. The agreement is excellent and implies that the DT produces comparable results if the appropriate geometry and fixtures are used. It is notable that the values for the thicker sections of $\mathrm{SiC}$ are slightly lower. This may be a result of the use of notches and the correction factor eq. (3) that assumes full interaction between the crack faces.

Figure 5(b) makes the comparison for alumina. The discrepancy is significant, even for thin sections. This probably results from the long cracks employed and the R-curve behavior observed for this alumina ${ }^{6}$. Some nonlinearity in the elastic portion of the load-displacement 

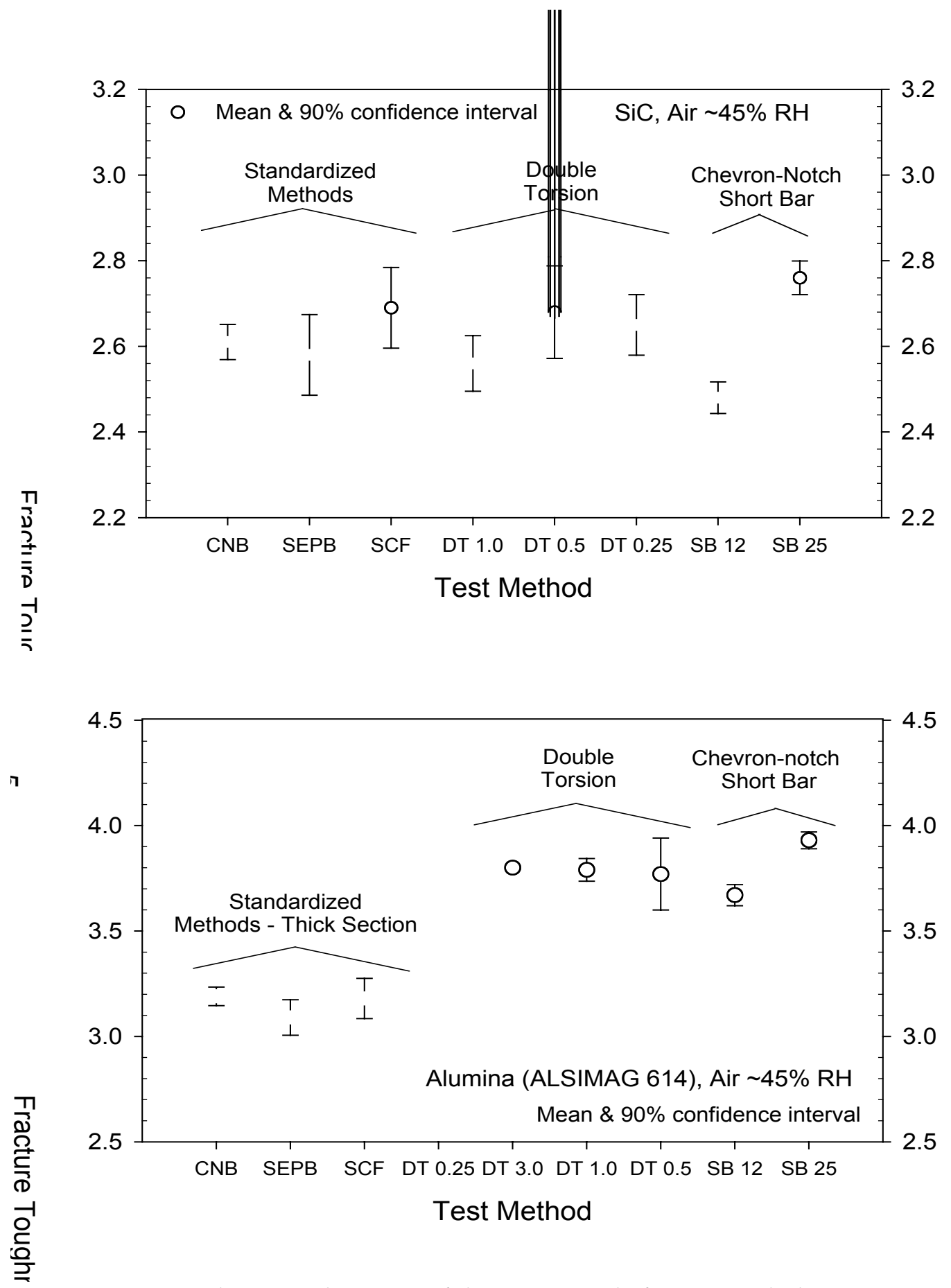

Figure 5 - Fracture toughness and 90\% confidence intervals for SiC and alumina in 45\% RH air as a function of test method. $C N B=$ chevron-notch in bending; SEPB = single-edgedprecracked-beam; $S C F=$ surface crack in flexure; DT $3.0=$ double torsion with $d=3.0 \mathrm{~mm} ; S B$ 12 = chevron-notch short bar with 12 mm thickness. 
curves could be observed for the thinnest specimens $(d=2.5 \mathrm{~mm}, a / L \approx 0.4)$, implying that a ratio of $\delta / d<0.4$ needs to be maintained for stiff, brittle materials. However, a significant effect of the nonlinearity could not be observed on the measured fracture toughness $(2.65 \pm 0.04$ $\mathrm{MPa} \sqrt{\mathrm{m}}$ ). Thin sections of materials with higher toughness and lower elastic modulus will likely require further consideration.

\section{DISCUSSION}

The double torsion test is commonly perceived as giving elevated values of fracture toughness. For instance a value of $3.84 \pm 0.05 \mathrm{MPa} \sqrt{\mathrm{m}}$ was reported for ALSIMAG alumina ${ }^{7}$ and values from $2.76 \pm 0.05$ to $4.6 \pm 0.13 \mathrm{MPa} \sqrt{\mathrm{m}}$ were reported for $\alpha \mathrm{SiC}^{8-10}$ Elevated values can result from friction at the load points, small $a / L$, small $W / d$, and the use of notches instead of precracks. The use of cracks outside the constant $K_{I}$ regime should also result in more scatter unless the cracks have very similar lengths. Long or curved cracks reduced the measured fracture toughness in this study. Material affects such as crack growth resistance and stress corrosion increase and decrease, respectively, the measured fracture toughness. The good agreement between the C1421 test methods and the DT for all thicknesses of SiC implies that use of appropriate test procedures will ensure good results for flat R-curve materials. The elevated values for the alumina relative to the $\mathrm{C} 1421$ values concur with previous long crack values ${ }^{4,6}$ from chevron-notch short bar specimens (3.67 to $3.93 \mathrm{MPa} \sqrt{\mathrm{m}}$ ), implying that good results representative of long cracks are obtained with good practice.

Based on the results in this study, $8<W / d<80, L / W>2,0.35<a / L<0.65$ are required if formulas not considering crack length are to be used. The narrow range of $a / L$ recommended is required for $L / W=2$, however, for larger $L / W$, a wider range is acceptable. ${ }^{3}$ Very large $L / W$ ratios will likely produce large constant $K_{I}$ regions; however, the mass of the test specimen may begin to affect the result. Load point friction needs to be minimized via free bearing balls. Side grooves are not needed with careful alignment of a well made fixture. The recommended crack length is compared for various geometries in Table II in terms of the normalized crack length $a / L$. When the criteria are written in terms of $a / L$, the widest ranges of $a / L$ tend to correspond to the largest $L / W$, however, some discrepancies can be noted, and may relate to the use of the total length of the plate rather than the length from the loading point. The upper end $a / L$ from this work is in agreement with those in Table II, however, the lower range from this work is more conservative. In general it can be concluded from Table II that $a / L$ between and will insure good results for wide range of $W / d$ and $L / W$.

A general guideline of the required thickness for linear elastic behavior can be derived by normalizing the deflection to the stress intensity (eq. 2) at failure and writing the plate deflection as a fraction of the plate thickness. The equation for load point displacement ${ }^{2}$ is

$$
\ddot{a}=\frac{3 P W_{m}^{2} a}{i W d^{3} \varnothing}
$$

where $P$ is the applied force, $d$ the plate thickness, $W$ the plate width, $W_{m}$ the moment arm, $a$ the crack length, and $\mu$ the shear modulus. The ratio of displacement to stress intensity at failure is 


$$
\frac{\ddot{a}}{K_{I d t}}=\frac{3 W_{m} a}{i W d^{3} \varnothing} \cdot\left[\frac{3(1+i)}{W d^{4} \varnothing}\right]^{-1 / 2}
$$

Substituting $\mu=3 E(1+), a=W$, and setting the allowable deflection to $d / 10$ gives the criterion

$$
d_{\text {min }} \cong \sqrt{\frac{9 K_{I d t}}{E(1+i)^{3 / 2}} \frac{W_{m} W}{\emptyset^{1 / 2}}} .
$$

where $E$ is Young's modulus. Because the case of interest is usually thin stiff plates, $\psi$ will typically be $\sim 1$. For $\mathrm{SiC}\left(E=395 \mathrm{GPa}, v=0.17, K_{\text {Idt }}=2.6 \mathrm{MPa} \sqrt{\mathrm{m}}, W_{m}=7.5 \mathrm{~mm}\right.$ ), eq. (4) gives $d_{\text {min }}=0.23 \mathrm{~mm}$, nominally comparable to the thickness exhibiting nonlinearity in this study.

Table II. Normalized crack length range that produced consistent fracture toughness via equation (1).

\begin{tabular}{|c|c|c|c|c|}
\hline$W / d$ & $L / W$ & $a / L$ range & Analysis Method \& Material Used & Reference \\
\hline 51 & 1.5 & $0.26<a / L<0.46$ & Fracture toughness tests, Glass & 12 \\
\hline 10 & 2 & $0.28<a / L<0.68$ & FEM & 9 \\
\hline 16 & 2.1 & $0.35<a / L<0.65$ & Fracture toughness tests, Glass & This work \\
\hline 32 & 2.4 & $0.20<a / L<0.59$ & " “ & 12 \\
\hline 17 & 3 & $0.20<a / L<0.75$ & " “ & 3 \\
\hline $25^{*}$ & 3 & $0.33<a / L<0.66$ & Slow crack growth tests, Mg-Al-Si & 3 \\
\hline 10 & 3 & $0.18<a / L<0.78$ & FEM & 9 \\
\hline 12 & 3.5 & $0.25<a / L<0.63$ & " “ & 13,14 \\
\hline \multicolumn{7}{|c|}{ * The test specimens were 2 mm thick, but contained a 1 mm deep side groove. } \\
\hline
\end{tabular}

\section{CONCLUSIONS}

Double torsion testing can produce fracture toughness values without crack length measurement that are comparable to those measured via ASTM C1421 if the appropriate geometry is employed, and the material exhibits little crack growth resistance. Results to date indicate that $8<W / d<80$ and $L / W>2$ are needed if crack length is not considered in the stress intensity calculation. At $L / W=2$, the normalized crack length should be $0.35<a / L<0.65$; whereas for $L / W=3,0.2<a / L<0.75$ is acceptable. For materials exhibiting crack growth resistance, values corresponding to the plateau of the R-curve are likely to be measured. The load points should be free to roll so that friction is minimized, and the plate thickness should be measured carefully. For very thin plates, $(W / d>80)$ nonlinear effects are likely to be encountered, depending on the stiffness and fracture toughness. One way to minimize the effect is to shrink the test specimen proportionally; however, alignment issues are likely to be exacerbated. 


\section{ACKNOWLEDGEMENT}

This work was funded by the Low Emission Alternative Power Program at NASA Glenn Research Center and by US Department of Energy, Office of Fossil Energy, SECA Core Technology Program at ORNL under Contract DE-AC05-00OR22725 with UT-Battelle, LLC. The authors are grateful to Chris Coffer of ORNL for help with pre-cracking the test specimens.

\section{REFERENCES}

1. ASTM C 1421, "Standard Test Method for Determination of Fracture Toughness of Advanced Ceramics at Ambient Temperatures" Annual Book of Standards, Vol. 15.01 (American Society for Testing and Materials, West Conshohocken, PA, 2001) pp. 641-672.

2. E.R. Fuller, Jr., "An Evaluation of Double Torsion Testing: Analysis,” pp3-18 in Fracture Mechanics Applied to Brittle Materials, STP678, S.W. Frieman, ed., ASTM, Philadelphia, Penn, 1979.

3. B.J. Pletka, E.R. Fuller, Jr., and B.G. Koepke, “An Evaluation of Double Torsion Testing: Experimental," pp19-37 in Fracture Mechanics Applied to Brittle Materials, STP 678, S.W. Frieman, ed., ASTM, Philadelphia, Penn, 1979.

4. J.A. Salem, G.D. Quinn, M.G. Jenkins, "Measuring the Real Fracture Toughness of Ceramics: ASTM C1421,", pp. 531-553 in Fracture Mechanics of Ceramics: Active Materials, Nanoscale Materials, Composites, Glass, and Fundamentals, R.C. Bradt, D. Munz, M. Sakai and K. White, eds., Springer, (2005).

5. R.B. Tait, P.R. Fry, and G.G. Garrett, "Review and Evaluation of the Double Torsion Technique for Fracture Toughness and Fatigue Testing of Brittle Materials, Experimental Mechanics, pp.14-22, March 1987.

6. J.A. Salem, J.L. Shannon, Jr. and R.C. Bradt, "Crack Growth Resistance of Textured Alumina," Journal of the American Ceramic Society, 72, [1], pp. 20-27 (1989).

7. G.K. Bansel, W.H. Duckworth, "Fracture Stress as Related to Flaw and Fracture Mirror Sizes," Journal of the American Ceramic Society, 60, [7-8], pp. 304-310 (1977).

8. K.D. McHenry and R.E. Tressler, "Fracture Toughness and High Temperature Slow Crack Growth in SiC," J. Am. Ceram. Soc. 63 [3-4] 152-156 (1980).

9. A.G. Evans and F.F. Lange, "Crack Propagation and Fracture Toughness in Silicon Carbide," J. Matls. Sci, 19, 1659-1664 (1975).

10. G.D. Quinn, National Institute for Standards and Technology, private communication by email, October 31, (2005).

11. G. G. Trantina, "Stress Analysis of the Double-Torsion Specimen,"J. Am. Ceram. Soc. 60 [7-8] 338-341 (1977).

12. D. Shetty and A.V. Virkar, J. Am. Ceram. Soc. 61 [1-2] 93-94 (1978).

13. L.S. Li, R.F. Pabst, "Subcritical Crack Growth in Partially Stabilized Zirconia (PSZ)," J. Materials Science, 15, 2861-2866, (1980).

14. L.S. Li, J. Weick, and R.F. Pabst, Berichte der DKG, Ges 57, 5 (1980). 